\title{
Cyclosporine and Amlodipine
}

\section{Induced Severe Gingival Overgrowth -} Etiopathogenesis and Management of a Case with Electrocautery and Carbon-Dioxide $\left(\mathrm{CO}_{2}\right)$ Laser

\author{
Rashmi Hegde', Rahul Kale², A Sanjay Jain ${ }^{3}$
}

\begin{abstract}
Gingival overgrowth is a well recognized, unwanted side-effect associated with three major drugs/drug groups phenytoin, cyclosporine and the calcium channel blockers. Cyclosporine is a potent immunosuppressive compound that has been used increasingly in conjunction with kidney, heart and other transplants. Calcium channel blockers are widely used in medical practice for the management of cardiovascular disorders. Due to their wide range of use, gingival overgrowth is now a recognized side- effect associated with them. Here we discuss a case report dealing with severe gingival overgrowth induced by cyclosporine and amlodipine. A 36-year-old man who underwent renal transplant came with a chief complaint of generalized gingival swelling. He had very severe gingival overgrowth in both arches and required thorough scaling and oral hygiene instructions, followed by supportive periodontal therapy for 4 months, after which radical gingivectomy using electrocautery and $\mathrm{CO}_{2}$ laser was performed. The post operative results were excellent and there was no recurrence at 1 year follow-up.
\end{abstract}

Keywords: Cyclosporine, Amlodipine, Gingival overgrowth, Gingivectomy, Electrocautery, Carbon-dioxide $\left(\mathrm{CO}_{2}\right)$ laser

${ }^{1}$ MDS, Senior Lecturer,

Dept of Periodontology and Implantology

M.A.Rangoonwala College of Dental Sciences and

Research Centre, Pune, Maharashtra, India

${ }^{2} \mathrm{MDS}$, Senior Lecturer,

Dept of Periodontology and Implantology,

M.A.Rangoonwala College of Dental Sciences and

Research Centre, Pune, Maharashtra, India

${ }^{3}$ MDS, Professor

Dept of Periodontology and Implantology,

M.A.Rangoonwala College of Dental Sciences and

Research Centre, Pune, Maharashtra, India

\section{Contact Autbor}

Dr. Rashmi Hegde rashmidr21@yahoo.com

J Oral Health Comm Dent 2012;6(1)34-42

\section{INTRODUCTION}

ingival overgrowth is a well rec
ognized unwanted side-effect as
sociated with three major drugs / drug groups - phenytoin, cyclosporine and the calcium channel blockers. The prevalence of this unwanted effect varies between drugs, and a variety of risk factors have been identified in relation to the expression of drug-induced gingival overgrowth(1). It has been estimated that gingival overgrowth occurs in about $50 \%$ of patients taking phenytoin, $25-80 \%$ of patients taking cyclosporine, and 15-20\% of patients taking calcium channel blockers like Nifedipine and Amlodipine, but severe cases with nifedipine and amlodipine alone, occur in less than $1 \%(2,3)$. Gingival enlargement is thought to arise from overproduction of the ground substance formed by the fibroblasts (4).

Cyclosporine is a potent immunosuppressive compound that has been used increasingly in conjunction with kidney, heart and other transplants, and has been reported to be better tolerated than conventional therapy such as corticosteroids and cytotoxic drugs(5). To date, cyclosporine has been tested for treatment of insulin-dependent diabetes mellitus(6), Behcet's syndrome $(7,8)$, Psoriasis (9), Systemic Lupus Erythematosus(10), and other diseases(9). The major adverse reactions to cyclosporine 
therapy are nephrotoxicity, hepatoxicity, tremors, hirsutism, hypertension, mild anemia, gingival overgrowth and, in rare instances, lymphoma (11). Due to its variety of uses, cyclosporine-induced gingival overgrowth could become more common and thus of increasing interest to the periodontist. Of particular concern for the dental profession is the management of cyclosporine-induced gingival overgrowth, first reported in the dental literature in 1983(12). Cyclosporin selectively inhibits T-cell function, while having a minimal effect on humoral immunity (13).

Gingival over growth is also commonly associated with the use of many of the calcium channel blockers. Of this large group of drugs, the dihydropyridines are the agents most frequently implicated (14). Amlodipine, a newer agent of dihydropyridine, used for treatment of hypertension and angina, was first reported for causing gingival overgrowth as a side effect, by Seymour et al in 1994 (15).

Approximately $25-30 \%$ of patients medicated with cyclosporine experience this unwanted effect at a level severe enough to warrant surgical reduction of the gingival tissues (16). An increased prevalence of the condition occurs in patients concomitantly medicated with amlodipine (17). (18). The effect of calcium channel blockers on the severity of gingival overgrowth is now largely accepted (19) and appears to be related to the plasma concentration of the drug (20). A range of other risk factors for cyclosporine-induced gingival overgrowth has been identified (21) including age, sex, duration of therapy, gingival inflammation, genetic factors like cytochrome $\mathrm{P}_{450}, \mathrm{CSA}-\mathrm{HLA} \mathrm{DR}_{1}, \mathrm{CSA}-\mathrm{HLA} \mathrm{DR}_{2}, \mathrm{CSA}$ HLA A ${ }_{19}$, CSA-HLA $B_{37}$ and creatinine serum concentration. There is a wealth of literature relating directly to the role of cyclosporine in this effect but relatively little is known of the function of other immunosuppressive agents in gingival overgrowth.

\section{MECHANISM OF ACTION}

Cyclosporine is a selective immunosuppressant with a weak antimicrobial activity (22) and can be administered orally, intramuscularly or intravenously (23). The main use of cyclosporine is to prevent graft rejection in organ transplantation. Several studies have shown that cyclosporine selectively acts on the T-lymphocyte response, with little or no action on B lymphocytes (24).

\section{Role of Cyclosporine in Inhibition of Graft Rejection}

The pharmacodynamics of cyclosporine mainly involves the T-cell response. So it is essential to know the role of $\mathrm{T}$ lymphocytes in graft rejection(25). The mechanisms by which the T-lymphocytes reject the graft are shown in Figure 1.

Cyclosporine inhibits many of the stages shown in Figure 1, acting at both a cellular and molecular level. At low concentrations (10-20 ng/ml), it inhibits IL-2 synthesis, thereby limiting clonal amplification of cytotoxic T- lymphocytes. At a higher concentration (100 ng/ml), cyclosporine inhibits the ability of cytotoxic T- lymphocytes to respond to IL-2.The mechanism of this inhibition is uncertain, but may be due to the drug blocking the induction of IL-2 receptors on these cells. By contrast, cyclosporine has a sparing effect on suppressor $\mathrm{T}$ lymphocytes (26). Thus, $\mathrm{T}$ suppressor cells seem to be resistant to cyclosporine, whereas cytotoxic $\mathrm{T}$ lymphocytes and T-helper cells are sensitive to the drug (27).

Within the T-lymphocyte, cyclosporine binds to several proteins, in particular calmodulin and cyclophilin. It has been postulated that the resistance or sensitivity of $\mathrm{T}$ lymphocytes to cyclosporine may be related to the proportionate intracellular concentrations of calmodulin (involved in activation of T-lymphocytes) and cyclophilin (27). An increase in cyclophilin will increase cyclosporine binding, and thus prevent the drug from interacting with calmodulin. Conversely, low levels of cyclophilin will allow cyclosporine to bind to calmodulin and inhibit its formation and subsequent T-lymphocyte activation.

\section{CYCLOSPORIN AND GINGIVAL OVERGROWTH:}

The precise mechanism of cyclosporineinduced gingival overgrowth is uncertain. Various investigations for pathogenesis of

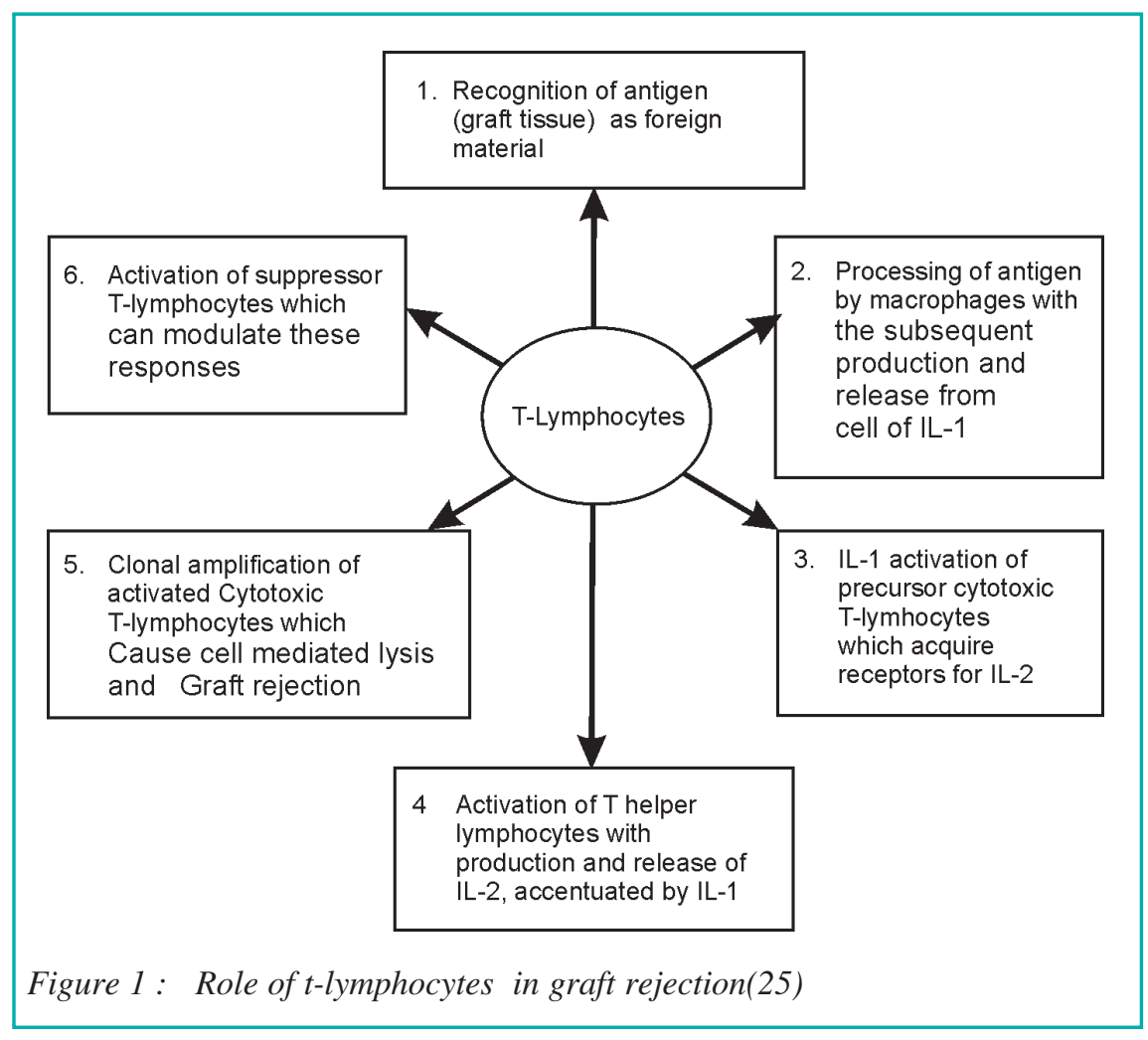


gingival overgrowth support the hypothesis that it is multifactorial(19). A possible model is shown in Figure 2(19).

Cell culture studies have shown that both cyclosporine and cyclosporine metabolites have direct effects on gingival fibroblast proliferation, protein synthesis and collagen production(25). Also, there exists a genetically determined subpopulation of cyclosporine sensitive gingival fibroblasts. Indeed, the terms "responders" and "nonresponders" have appeared in literature to identify those who show or do not show drug induced gingival changes (32). Both findings are important in the pathogenesis of cyclosporine-induced gingival overgrowth.

The results from clinical studies suggest that the incidence and severity of gingival overgrowth in cyclosporine treated patients is dependent upon the interaction of several factors. These include plaque control, the level of gingival inflammation and extent of periodontal destruction; the dosage and duration of cyclosporine therapy; plasma and tissue concentrations of the drug and metabolites; age of the patient and perhaps the underlying medical condition (25).

Some authors suggest that there is a significant relationship between amount of time without plaque control and development of gingival overgrowth (28), whereas others say no significant relation between cyclosporine induced gingival overgrowth and plaque scores (29). It is well known that lipopolysaccharide is an important component of bacterial cell wall which is known to be cytotoxic for fibroblasts.

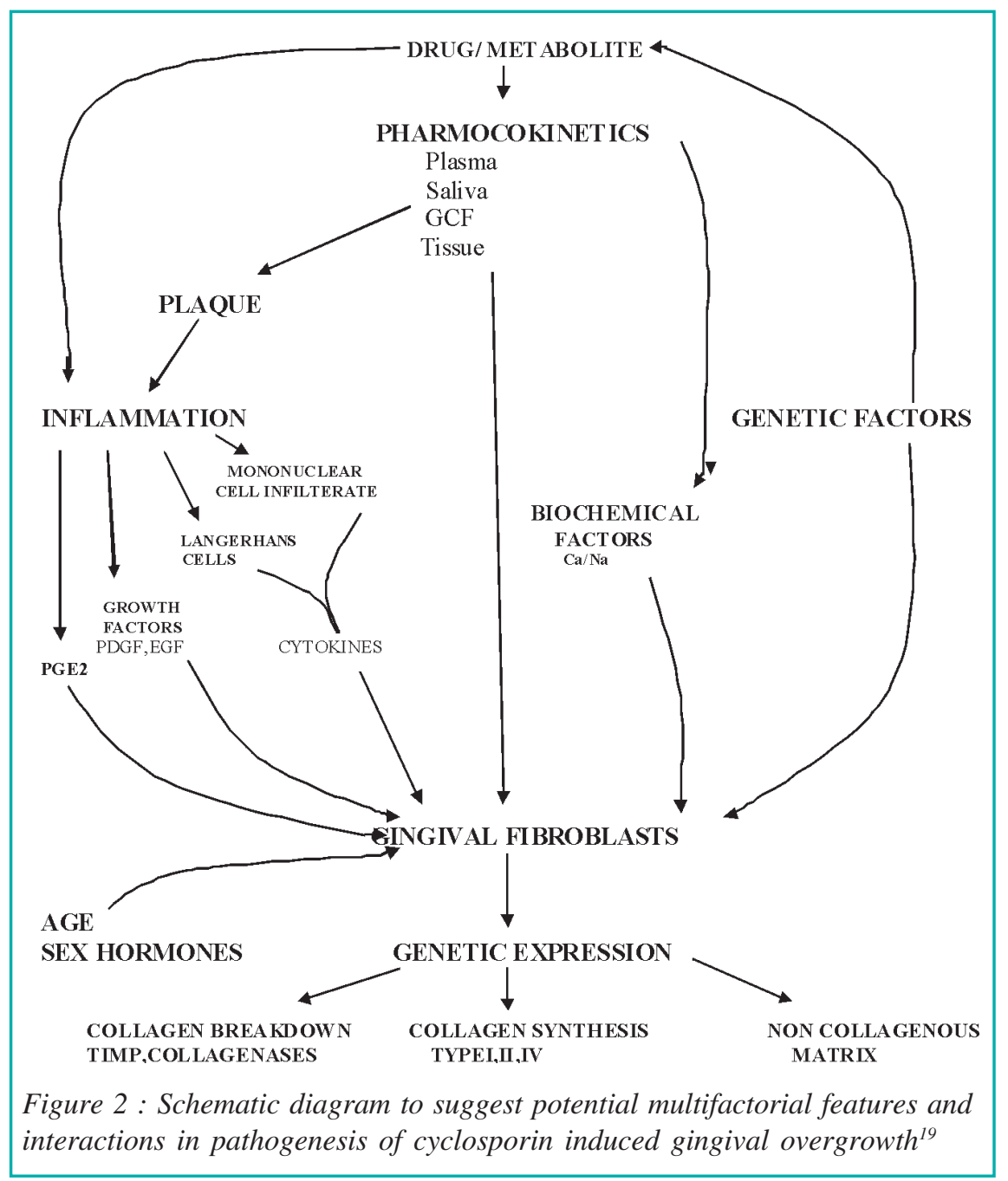

Cyclosporine enhances fibroblast DNA synthesis and cell proliferation and negates the effect of lipopolysaccharide on fibroblast cultures indicating a possible reason for the observed relationship between areas of prominent gingival overgrowth and dental plaque(30).

Cyclosporine-induced gingival overgrowth commences as a papillary enlargement which is more pronounced on the labial aspects of the gingiva than the palatal or lingual surfaces (31). The papillary enlargement increases and adjacent papillae appear to coalesce. This gives the gingival tissues a lobulated appearance. Overgrowth is restricted to the width of attached gingiva, but can extend coronally and interfere with the occlusion, mastication and speech. Cyclosporine induced gingival overgrowth has not been reported in edentulous subjects (32).

The hyperplastic gingival tissues often show marked inflammatory changes. They bleed readily on probing and are generally more hyperaemic than the gingival tissue from phenytoin-induced gingival overgrowth (25).

\section{AMLODIPINE AND GINGIVAL OVERGROWTH}

The pathogenesis of gingival overgrowth is uncertain and a number of factors affect the relationship between drug and gingival overgrowth.

\section{Role of Fibroblasts}

As only a subset of patients treated with amlodipine develop gingival overgrowth, it has been hypothesized that these individuals have fibroblasts with an abnormal susceptibility to the drug and the fibroblasts from overgrown gingiva in these patients are characterized by elevated levels of protein synthesis, most of which is collagen (33). It also has been proposed that susceptibility or resistance to pharmacologically induced gingival enlargement may be governed by the existence of differential proportions of fibroblast subsets in each individual which exhibit a fibrogenic response to amlodipine $(34,35)$. 


\section{Role of Inflammatory Cytokines}

A synergistic enhancement of collagenous protein synthesis by human gingival fibroblasts was found when these cells were simultaneously exposed to amlodipine and interleukin-1b (36). In addition to IL1b, IL-6 may play a role in the fibrogenic responses of the gingiva to amlodipine (37).

\section{Role of Matrix Metalloproteinase} (MMP) Synthesis and Function

Because most types of pharmacological agents implicated in gingival enlargement have negative effects on calcium ion influx across cell membranes, it was postulated that such agents may interfere with the synthesis and function of collagenases(38).

\section{PREVENTION AND TREATMENT OF GINGIVAL ENLARGEMENT}

\section{Prevention}

In the susceptible patient, drug-associated gingival enlargement may be ameliorated, but not prevented by elimination of local factors, meticulous plaque control, and regular periodontal maintenance therapy. A 3-6 month interval for periodontal maintenance therapy has been recommended for patients taking drugs associated with gingival enlargement (39). Each recall appointment should include detailed oral hygiene instructions and thorough prophylaxis, with supra-and subgingival calculus removal as needed (40).

It is important that the dental professional encourages improved tooth cleaning in a supportive and positive manner, as well as providing information about the role of dental plaque in promoting gingival overgrowth. Mild gingival enlargement will often diminish with removal of plaque and calculus deposits. Even moderate gingival enlargement may reduce enough to avoid surgical intervention. Attempts at improving oral hygiene are of limited benefit in severe gingival enlargement, as surgical gingival excision is generally indicated (41).

\section{TREATMENT}

\section{Drug Substitution/withdrawal}

The most effective treatment of drug-related gingival enlargement is withdrawal or substitution of medication. Many cases of gingival enlargement will respond to local treatment, but consideration should be given to altering the medication if gingival enlargement covers more than about a third of the tooth surface. When possible, reducing the dose or changing to another drug may bring about partial or complete regression of the lesion. Most patients will observe an alteration in the soft tissues within a few days(41). When this treatment approach is taken as suggested by another case report, it may take from 1 to 8 weeks for resolution of gingival lesions (42). Unfortunately, not all patients respond to this mode of treatment, especially those with long standing gingival overgrowth (43).

\section{Non-surgical Treatment}

Mild gingival enlargement may only require local management as improvement in oral hygiene, together with professional cleaning of the teeth, can lead to resolution of inflammation and reduction in gingival enlargement. Professional debridement with scaling and root planing as needed has been to shown to offer some relief in gingival overgrowth patients (44).

Treatment planning becomes more complex where there is periodontitis associated with gingival enlargement, which poses a cosmetic or functional problem. Periodontitis alone can be treated using conventional clinical care, but when associated with the gingival enlargement, may require changes in the medication regimen, periodontal surgery(flap technique)pocket elimination along with removal of excess tissue, or a combination of the two (41).

\section{Surgical Periodontal treatment}

Because the anterior labial gingiva is frequently involved, surgery is commonly performed for esthetic reasons before any functional consequences are present. The classical surgical approach has been the external bevel gingivectomy(33). However a total or partial internal gingivectomy approach has been suggested as an alternative (44). This is a more technically demanding approach, which has the benefit of limiting a large denuded connective tissue wound that results from the external gingivectomy, thereby minimizing postoperative inflammation, pain and bleeding.

The use of electrocautery and carbon dioxide lasers has shown some utility for reducing gingival enlargement, an approach which provides rapid post operative hemostasis(33). Consultation with the patient's physician prior to surgical treatment regarding antibiotic and steroid coverage should take place in the immunosuppressed patient (44).

\section{CASE REPORT CHIEF COMPLAINT}

A 36-year-old male patient reported to the Department of Periodontolgy and Implantology, M.A.Rangoonwala college of Dental Sciences and Research Centre, Pune with a chief complaint of gingival swelling all over his mouth. The swelling caused difficulties in speaking and eating and it also had obvious implications for his aesthetic appearance. Besides these, other complaints were pain, bleeding from gums, halitosis, and inability to brush and maintain his oral hygiene.

\section{CASE HISTORY FINDINGS}

Patient's medical history revealed that he sustained renal failure secondary to nephrotic syndrome in September, 1998. The patient was on hemodialysis since then for 3 years during 1998 to 2001. Renal transplantation was carried out on 20/9/2001, where the donor was his mother. He also had hypertension since 8 years and was on medication for the same. At the time the case history was recorded; the patient was on the medication as seen in table $1 . \mathrm{He}$ reported that the problem of gingival enlargement had begun 4-5years before, with slow progression to the present condition as seen in Figures 3 A, B, C.

\section{CLINICAL PRESENTATION}

The extraoral examination revealed a dismorphic face. The patient was unable to close his lips because of the protrusion of the enlarged tissues.

The intraoral examination revealed generalized, severe grade III gingival enlarge- 


\section{Table 1: Medication of the patient}

\begin{tabular}{|ll|}
\hline Drug & Dosage \\
\hline Liq. Neoral ( Cyclosporine) & $0.8 \mathrm{ml} \mathrm{b.d}$ \\
Tab. Azoran (Azithromycin) & $50 \mathrm{mg}$ o.d. \\
Tab. Wysolone (Corticosteroid) & $10 \mathrm{mg}$ o.d. \\
Tab. Amtas ( Amlodipine) & $10 \mathrm{mg}$ o.d. \\
Tab. Ecosprin (Aspirin) & $325 \mathrm{mg}$ o.d \\
Syrup Kesol (Ketoconazole) & $2 \mathrm{tsp}$ b.d. \\
Candid mouth pain (Nystatin) & t.d.s \\
\hline
\end{tabular}

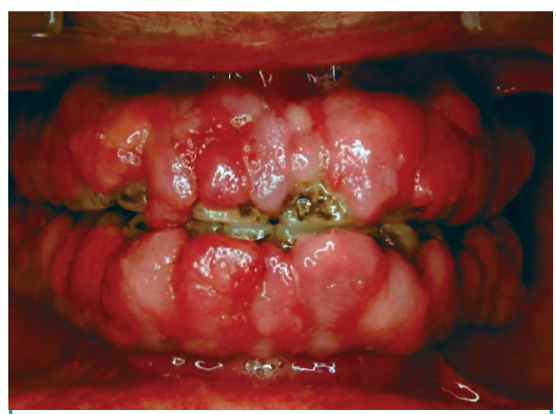

Figure 3A: Frontal view (Preoperative view)
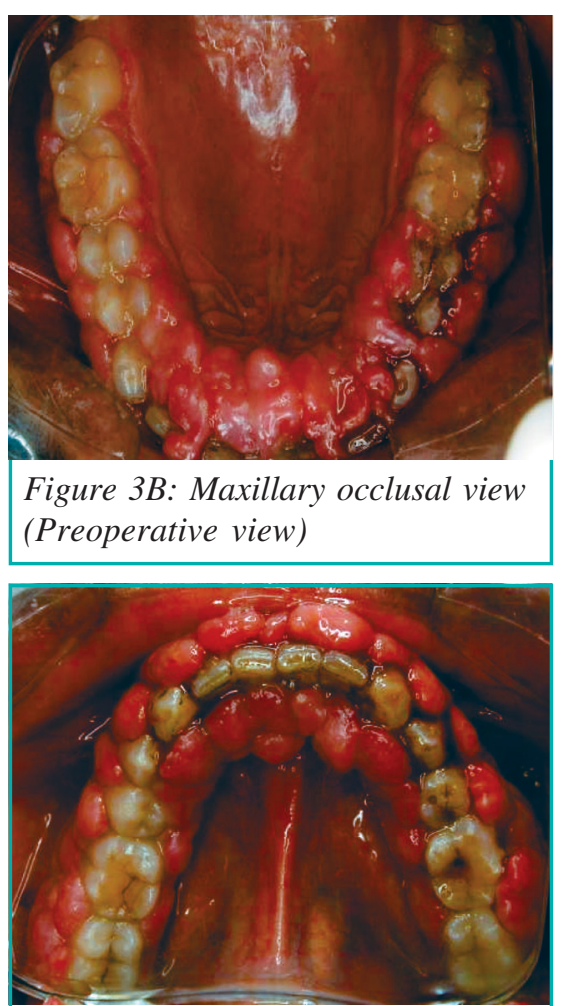

Figure 3C: Mandibular occlusal view (Preoperative view)

ment, as per the Bokenkamp gingival overgrowth index (45), involving both the mandibular and maxillary arches. In the maxilla and mandible, only the incisal and occlusal surfaces of the teeth, surrounded by large amounts of gingival tissue, were visible. The gingiva was highly inflamed, with a firm and dense consistency. Clinical examination revealed the presence of abundant local factors. There was spontaneous bleeding and in addition, halitosis was accentuated.

\section{INVESTIGATIONS}

The investigations carried out were complete haemogram, orthopantogram and biopsy.

- Haemogram: The haemogram showed all values within the normal variable range.

- Orthopantogram : There was mild bone loss associated, as revealed by orthopantogram in Figure 4

- Biopsy : The histopathology slide as seen in Figure 5.

- Histopathology report: The report showed pseudoepitheliomatous proliferation, collagenous material with thickening of epithelium, highly vascularized connective tissue and foci of inflammatory cells.

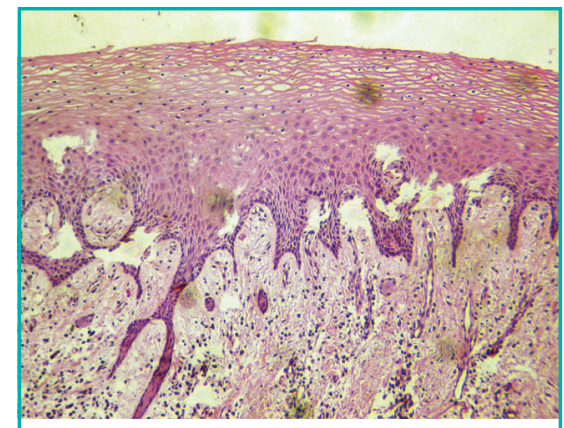

Figure 5: Gingival hyperplasia as seen histopathologically

Management of the gingival overgrowth

\section{Non-surgical Management}

After obtaining prior consent from the patient and physician, and controlling the other systemic factors, the patient was given intensive oral hygiene instruction which included tooth brushing three times a day, CHX mouthrinse $0.2 \%$ for 15 days twice daily and warm saline gargles three to four times a day. A thorough scaling using an ultrasonic scaler (EMS-Minipiezon) was performed at intervals of two weeks, for a period of 3 months.

Figure 6 shows the post operative view 1 month after Phase I therapy. Then the patient was treated with external bevel gingivectomy using electrocautery with loop and needle electrode (Whaledent, Perfect TCS) in the first quadrant and the other three quqdrants were not treated. The electro-

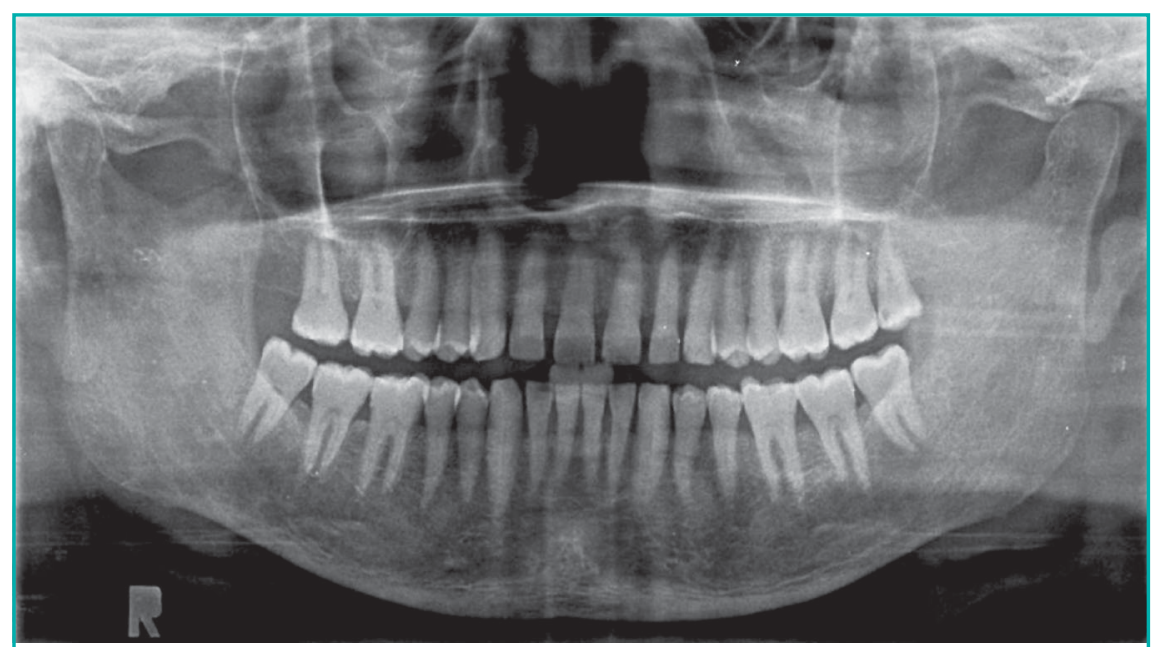

Figure 4: Orthopantogram revealing mild bone loss 


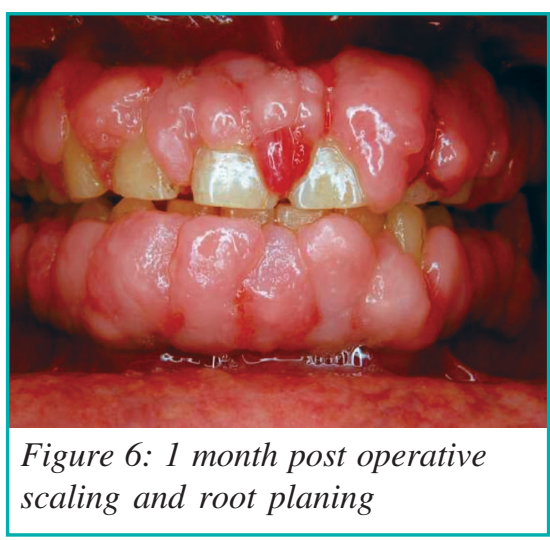

cautery was used in cutting and coagulation mode at the settings of 4 . This was done so as to compare the effect of surgical versus non surgical treatment on the gingival overgrowth. Then the patient was kept on Supportive periodontal therapy for 3 months. It was observed, that at the end of 4 months following Phase I therapy, the tissues appeared pink, firm, and devoid of any signs of inflammation. The non surgical therapy had shown a considerable reduction in the size of the overgrowth however, the amount of enlargement that persisted, warranted surgical intervention for its resolution, as seen in Figure 7. Because the patient was unhappy with the appearance of his gingivae and there was persistent residual overgrowth, it was decided to treat the problem surgically by using the gingivectomy technique for excision of the gingival overgrowth.

\section{Surgical Management}

The use of a traditional scalpel surgical approach was contraindicated by the phycisian because it was considered that bleeding would have been more severe and healing slow, with increased chances of post-op-

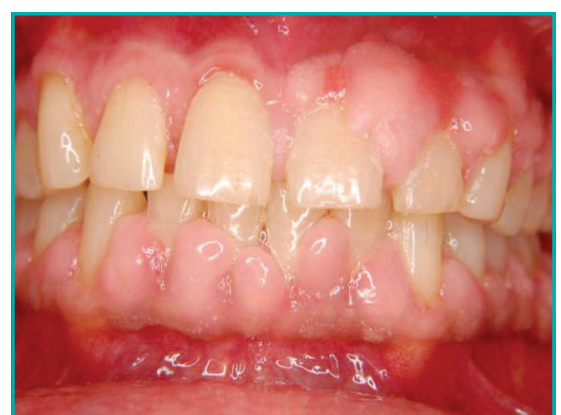

Figure 7: 4 months postoperative scaling and root planing

erative infection in an immunosuppressed patient. As per the physician, the drug regime for the patient could not be changed or modified, as all the drugs were essential for the patient. So the drug dosage were not reduced, neither was the drug substituted. The patient was on aspirin, which was stopped 10 days prior to the surgical procedure.

The overgrowth was then excised by external bevel gingivectomy using electrocautery with loop and needle electrode (Whaledent, Perfect TCS). The electrocautery was used in cutting and coagulation mode at the settings of 4 (Figure 8). Very good immediate post-operative result was obvious. After 1 month, following healing, gingivoplasty was carried out using $\mathrm{CO}_{2}$ laser(Union Medical, Korea) at 2-4 Watts, continuous wave, and in the focused mode (Figure 9 A,B,C).

The patient maintained excellent oral hygiene and six months later, was free of plaque and gingivitis in the area of his surgery (Figure 10). One year follow up (Figure 11) revealed that there were no sigits of recurrence of the gingival overgrowth and

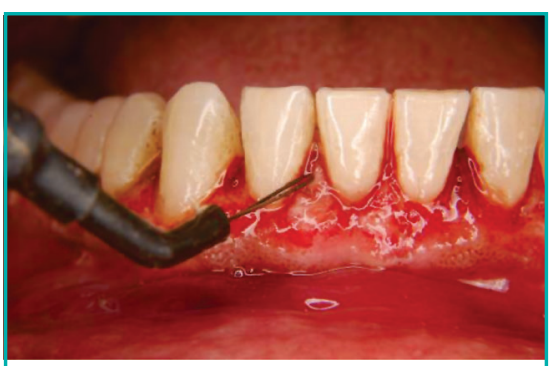

Figure 8: Gingivectomy using electrocautery

the tissues appeared remarkably healthy. Figure 12 and 13 shows the preoperative and postoperative results.

\section{DISCUSSION}

This is a review and report of a case of cyclosporine and amlodipine induced gingival overgrowth. A number of features of this case merit discussion.

First, prevention of dental plaque accumulation by tooth brushing three times a day, oral rinsing with antiseptic solutions and ultrasound scaling whenever necessary make the reccurrence of inflammation and gingival overgrowth less likely. In this case report, the reccurrence of inflammation and gingival overgrowth is not seen as the patient maintained excellent oral hygiene. Gingival inflammation following bacterial plaque seems to exacerbate drug-induced gingival overgrowth. Poor oral hygiene is an important risk factor for the expression of drug induced gingival overgrowth (46, 47, 48, 49). Most reports on the relationship between bacterial plaque and gingival overgrowth have been derived from crosssectional studies, but there is no clear evidence that bacterial plaque is a contributory factor or a consequence of the gingival changes $(50,51,52)$. However, it can be

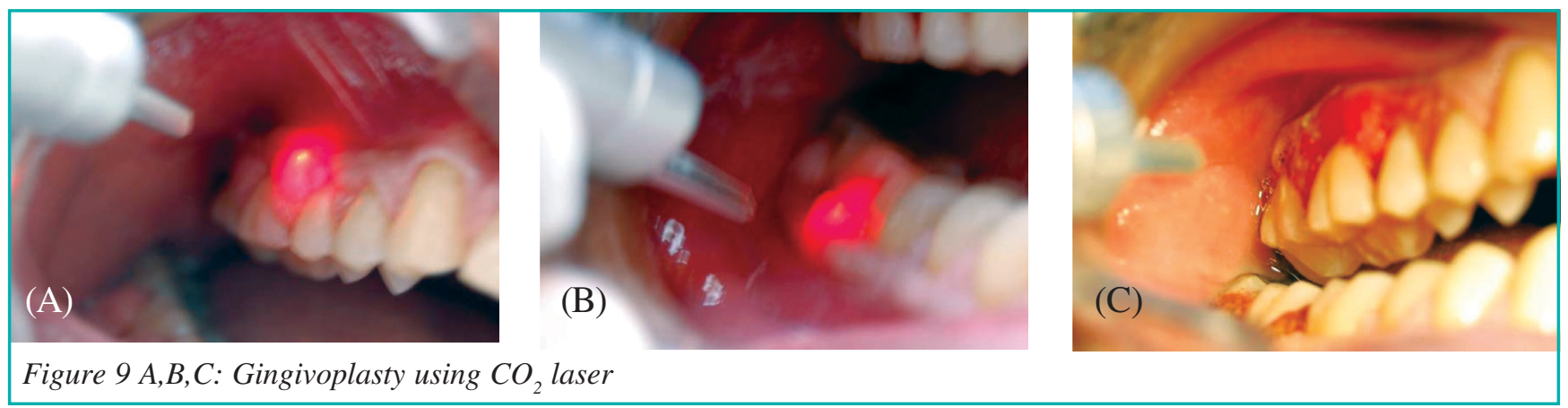




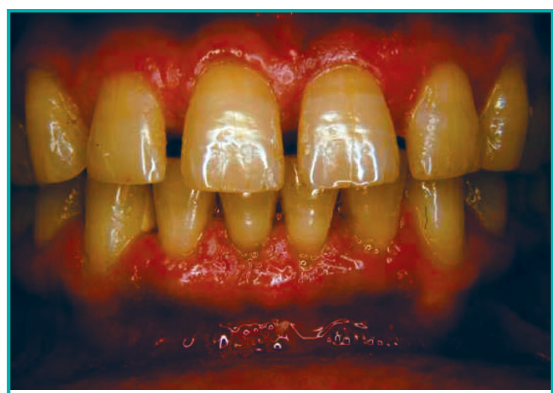

Figure 10: 6 months postoperative gingivectomy

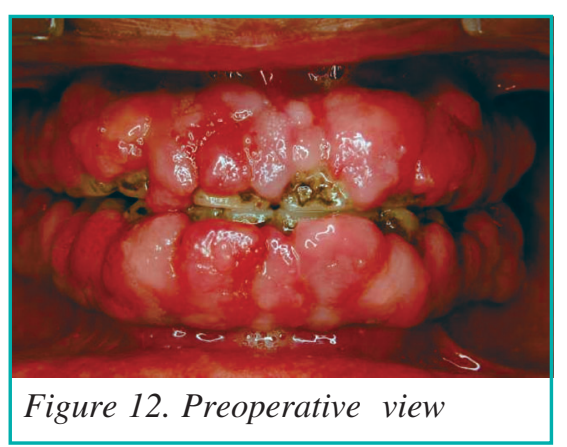

assumed that adequate oral hygiene could delay the development of cyclosporine and amlodipine induced gingival overgrowth, possibly by eliminating the lesion-specific inflammatory component. Nevertheless, it may well be that improved oral hygiene alone cannot prevent gingival overgrowth $(19,49,50)$.

Second, it should be noted that post-operative bleeding was insignificant. Electrosurgery techniques have been used in dentistry for the past 70 years. Although such techniques produce adequate haemostasis, they have the disadvantage of causing a surrounding zone of thermal necrosis, which may impede wound healing (53). Reports in the literature have confirmed delayed healing of electrosurgery wounds when compared with scalpel wound healing (54). This is probably due to the production and accumulation of excessive latent heat, which can be significant if electrosurgery is performed inappropriately. The amount of latent heat produced is dependant upon instrumentation variables, such as type of waveform, size of cutting electrode, time required for incision and the energy produced at operating site (55). Nevertheless, surgical intervention
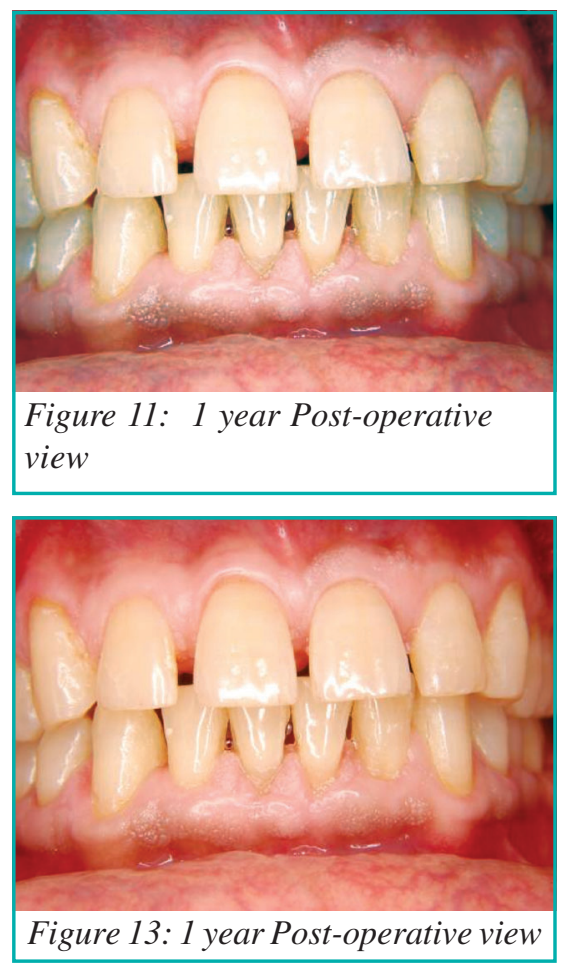

using conventional means (scalpel) may sometimes be technically difficult and/or impractical for example in children or mentally handicapped, or in immunosuppresed patients or those suffering from impaired haemostasis. In these situations, the use of electrosurgery may be advantageous (56). This therapy is only slightly invasive, the aesthetic improvement is immediate, and sutures and dressings are unnecessary (54). Following the procedure, the patient reported that pain from the gingival overgrowth disappeared, bleeding was almost absent, and consequently the patient's discomfort was eliminated. The fact that electrocautery surgery ensures disinfection, sterilisation of dental tissues with reduction of bacterial viability, and rapid haemostasis is an important consideration with regard to the prevention of post-operative infection, especially in immunosuppressed patients.

Third, there was no reccurrence of the gingival overgrowth even after one year follow up in our case report. There are high chances of recurrence of gingival overgrowth, when the excision is done by external bevel gingivectomy as the effects of cyclosporine and calcium channel blockers are seen on more extensive and unprotected healing area (57). Laser treatment on oral soft tissues results in a thin layer of carbonized tissue and formation of collagen slough that protects the underlying tissue (58). The chances for recurrence of gingival overgrowth are minimized or delayed when laser gingivectomy is done, as cellular mitotic activity starts from within the connective tissue, therefore more time will be required for gingival enlargement to manifest clinically as compared to scalpel gingivectomy(59). In a study by Seymour et al 2006, where he compared scalpel gingivectomy with flap surgery and $\mathrm{Nd}$ :YAG laser gingivectomy, he found that the recurrence following laser therapy was least as compared to other groups during 1-3 months duration(60). Our case report coincides with this study as gingivoplasty by $\mathrm{CO}_{2}$ laser resulted in no recurrence. It was also attributed to the excellent oral hygiene maintainence by the patient.

It was thus significant that $\mathrm{CO} 2$ laser gingivoplasty in combination with excellent oral hygiene resulted in no recurrence of the gingival overgrowth.

The patient in this case report practised good oral hygiene after ultrasonic scaling and professional cleaning, and this clearly demonstrated a beneficial effect. Excision of the overgrown tissue resulted in the total removal of the gingival overgrowth.

\section{CONCLUSIONS}

Gingival overgrowth is a side-effect of the long-term administration of cyclosporine and amlodipine and may also be influenced by other predisposing factors, such as bacterial plaque. In this case report, inspite of the effect of Polypharmacy, using combination of various drugs like cyclosporine and amlodipine aggravating the gingival overgrowth in the presence of plaque and other local factors, the use of non surgical therapy and surgical therapy facilitated optimal reduction of overgrown gingival tissue, with very good results, improved esthetics and no overgrowth after one year follow up. It needs to be emphasized that elimination of local factors followed by thorough maintainance has a definitive significant inhibitory effect on gingival 
overgrowth. Surgical treatment to excise and remodel the gingival contour should be considered whenever gingival overgrowth causes aesthetic and functional problems. The use of an electrocautery and $\mathrm{CO}_{2}$ laser for removal of gingival overgrowth surgically decreases intra-operative haemorrhage and has excellent postoperative results.

\section{REFERENCES}

1. Seymour RA, Ellis JS, Thomason JM. Risk factors for drug-induced gingival overgrowth. Journal of Clinical Periodontology 2000;27:217-23.

2. Lawrence DB, Weart W, Laro JJ, Neville BW. Calcium channel blocker-induced gingival hyperplasia: case report and review of this iatrogenic disease. $J$ Fam Practice 1994;39:483-88.

3. Johnson RB. Nifedipine-induced gingival overgrowth. Ann Pharmacother 1997;31:935.

4. Lucas RM, Howell LP, Wall BA. Nifedipine induced gingival hyperplasia: A histochemical and ultrastructural study. J Periodontal 1985;56:211-15.

5. Ryffel B, Donatsch $\mathrm{P}$, Nadorin $\mathrm{M}$, et al. Toxicological evaluation of cyclosporineA. Arch Toxicol 1983;52:107-41.

6. Stiller CR, Dupre J, Gent M, et al. Effects of cyclosporine immunosuppression in insulin-dependent diabetes mellitus of recent onset. Science 1984;223:136267.

7. Nussenblatt RB, Palestine AG, Rook A, et al. Treatment of intra-ocular infiammatory disease with cyclosporine-A. Lancet 1983;2:235-38.

8. French-Constant C, Wolman R, Geriat James D. Cyclosporine in Behcet's disease (letter). Lancet 1983;2:454.

9. Daley T, Wysocki G, Cyclosporine therapy: its significance to the periodontist. J Periodontol 1984;55:70812.

10. Isenberg DF, Snaith $\mathrm{M}, \mathrm{Al}-\mathrm{Khader} \mathrm{A}$, et al. Cyclosporine relieves arthralgia, causes angiodema (letter). A' Engl J Med 1980;303:754.

11. Sooriyamoorthy M, Gower DB, Eley BM. Androgen metabolism in gingival hyperplasia induced by nifedipine and cyclosporine. J Periodont Res 1990;25; 25-30.

12. Rateitschak-Plu" ss, EM Hefti A, Lo"rtscher R, Thiel G. Initial observation that cyclosporine-A induces gingival enlargement in man. Journal of Clinical Periodontology 1983;10:237-46.

13. Borel J, Wiesinger D. Studies on the mechanism of action of cyclosporine-A. (Proceedings). $\mathrm{Br} J$ Pharmacol 1979;66:66-67.

14. Seymour RA, Ellis JS, Thomason JM,
Monkman S, Idle JR. "Amlodipine induced gingival overgrowth." Journal of Clinical Periodontology 1994;21:281-83.

15. Seymour RA "Calcium channel blockers and gingival enlargements" $\mathrm{Br}$ Dent $J$ 1991;170:376-79.

16. Thomason JM. Drug-induced gingival overgrowth in organ transplant patients PhD. Newcastle Upon Tyne 1995.

17. Slavin J, Taylor J. Cyclosporine, nifedipine, and gingival hyperplasia [letter]. Lancet 1987;2:739.

18. Thomason J M, Seymour RA, Rice N. The prevalence and severity of cyclosporine and nifedipine-induced gingival overgrowth. Journal of Clinical Periodontology 1993;20:37-40.

19. Seymour RA, Thomason JM, Ellis JS. The pathogenesis of drug-induced gingival overgrowth [review]. Journal of Clinical Periodontology 1996;23:165-75.

20. Thomason JM, Ellis JS, Kelly PJ, Seymour RA. Nifedipine pharmacological variables as risk factors for gingival overgrowth in organ-transplant patients. Clinical Oral Investigations 1997; 1:35-39.

21. Thomason JM, Seymour RA, Ellis JS, Kelly PJ, Parry G, Dark J, Idle JR. latrogenic gingival overgrowth in cardiac transplantation. Journal of Periodontology 1995;66:742-46.

22. Borel JF, Feurer C, Gubler HU. Biological effects of cyclosporine A: A new antilymphocyte agent. Agents and Actions 1976;6:468-75.

23. Beveridge T, Gratwohl A, Michot F. Cyclosporine A: pharmacokinetics after a single dose in man and serum levels after multiple dosing in recipients of allogenic bone marrow grafts. Current Therapeutics Research 1981;30:5.

24. Britton S, Palacios R. Cyclosporine A usefulness, risks and mechanisms of action. Immunologicai Review 1982;65: 5-22.

25. Seymour RA, Jacobs DJ. Cyclosporine and the gingival tissues. J Clin Periodontol 1992;19:1-11.

26. Hess AD, Tutschka PJ, Santos GW. The effect of cyclosporine A on Tlymphocyte subpopulations. In: Cyclosporine A, ed, D, J, G, White, pp, 1982;209-32, Elsevier, Amsterdam.

27. Hess AD, Colombani PM. Mechanism of action of cyclosporine: a unifying hypothesis. Advances in Experimental Medicine and Biology 1987;213:309-330.

28. Modeer T, Dahloff G. Development of phenytoin induced gingival overgrowth in non-institutionalized epileptic children subjected to different plaque control programs. Acta Odontologica Scandinavica 1987;45:81-85.

29. Seymour RA, Smith DG. The effect of plaque control programme on the incidence and severity of cyclosporine induced gingival changes. Journal of Clinical Periodontology 1991;18:107-10.
30. Bartold PM. Regulation of human gingival fibroblast growth and synthetic activity by cyclosporine A in vitro. Journal of Periodontal Research 1989;24:314-21.

31. Tyldesley WR, Rotter E. Gingival hyperplasia induced by cyclosporine A. British Dental Journal 1984;157:305309.

32. Friskopp J, Klintmalm G. Gingival enlargement: A comparison between cyclosporine and azathioprine treated renal allograft recipients, Swedish Dental Journal 1986; 10:85-92.

33. Grover V, Kapoor A, Marya CM. Amlodipine Induced Gingival Hyperplasia: J Oral Health Comm Dent 2007; 1(1):1922.

34. Hassel TM, Page RC, Narayanan AS, Cooper CG. Diphenylhydantion (Dilantin) gingival hyperplasia; Drug-induced abnormality of connective tissue. Proc Natl Acad Sci (USA) 1976;73:2909-12.

35. Sinha-Morton R, Dongri-Bagtzoglou Al. Regulation cyclosporine A. J Periodontol 1998;69:899-910.

36. Johnson RB, Zebrowski EJ, Dai X. Synergistic enhancement of collegenous protein synthesis by human gingival fibroblasts exposed to nifedipine and interleukin-1-beta in vitro. J Oral Pathol Med 2000;29:8-12.

37. Williamson MS, Miller EK, Plemons J, Rees T, lacopino AM. Cyclosporine A upregulates interleukin-6 gene expression in human gingiva: Possible mechanism for gingival overgrowth. $J$ Periodontol 1994;11:552-60.

38. Hassel TM. Evidence for production of an inactive collagenase by fibroblasts from phenytion-enlarged human gingiva. J Oral Pathol 1982;11:310-17.

39. Hall EE. Prevention and treatment consideration in patients with druginduced gingival enlargement. Curr Opin Periodontol 1997;4:59-63.

40. Boraz RA. A dental protocol for the pediatric cardiac transplant patient. ASDC J Dent Child 1986;53:382-85.

41. Barbara Anne Taylor, Management of drug-induced gingival enlargement: Aust Prescr 2003;26:11-3.

42. Khocth A, Schneider LC. Periodontal management of gingival overgrowth in the heart transplant patient: A case report. J Periodontal 1997;68:1140-46.

43. Marshall RI, Bartold PM. A clinical review of drud-induced gingival overgrowth. Oral Surg Oral Med Oral Pathol 1993; 76:543-48.

44. Somacarrera ML, Lucas M, Scully C, Barrios C. Effectiveness of periodontal treatments on cyclosporine induced gingival overgrowth in transplant patients. Br Dent J 1997; 183:89-94.

45. Bokenkamp A, Bohnhorst B, Beier C, et al. Nifedipine aggravates cyclosporine A-induced hyperplasia. Pediatr Nephrol 1994;8:181. 
46. Marriotti A. Dental plaque-induced gingival disease Annals of Periodontology 1999;4:7-17.

47. Marshall RI, Bartold PM. A critical review of drug induced gingival overgrowth. Australian Dental Journal 1999;44:21932.

48. McCulloch CA, Bordin S. Role of fibroblast subpopulations in periodontal physiology and pathology. Journal Periodontal Research 1991;26:144-54.

49. Seymour RA, Smith DG. The effect of a plaque control programme on the incidence and severity of cyclosporininduced gingival changes. Journal of Clinical Periodontology 1991; 18:107-10.

50. Hassell TM, Hefti AF. Drug-induced overgrowth: Old problem, new problem. Critical Reviews in Oral Biology and Medicine 1991;2:103-37.

51. Piferi M, Veraldi S, Silvestri E, Ambroso G, Marini D. Iperplasia gingivale da nifedipina: Fattori predisponenti (Gingival hyperplasia caused by nifedipine: Predisposing factors). Mondo Odontosmatol 1987;4:41-44.

52. Ramon Y, Behar S, Kishon Y, Engelberg I. Gingival hyperplasia caused by nifedipine-a preliminary report. Int $J$ Cardiol 1984;4:195-204.

53. Mavrogiannis M, Ellis JS, Thomason JM, Seymour RA. The management of drug induced gingival overgrowth. J Clin Periodontol 2006;33:434-39.

54. Liboon J, Funkhouser W, Terris DJ. A comparison of mucosal incisions made by scalpel, $\mathrm{CO} 2$ laser, electrocautery, and constant-voltage electrocautery. Otolaryngol Head Neck Surgery 1997;116:379-85.

55. Krejci RF, Kalkwarf KL, KrauseHohenstein U. Electrosurgery-a biological approach. Journal of Clinical Periodontology 1987; 14:557-63.

56. Walker C Jr, Tomich CE, Hutton CE. Treatment of phenytoin-induced gingival hyperplasia by electrosurgery. Journal of Oral Surgery 1980;38:306-11.

57. Pilloni A, Camargo PM, Carere M, Carranza FAJ. Surgical treatment of cyclosporine A-and nifedipine-induced gingival enlargement: gingivectomy versus periodontal flap. Journal of Periodontology 1998;69:791-97.

58. Romanos G E, Nentwig GH. Present and future of lasers in oral soft tissue surgery: clinical applications. Journal of Clinical Laser Medicine and Surgery 1996; 14:179-84.

59. Darbar UR, Hopper C, Speight PM, Newman HN. Combined treatment approach to gingival overgrowth due to drug therapy. Journal of Clinical Periodontology 1996;23:941-44.

60. Mavrogiannis M, Ellis JS, Seymour RA, Thomason JM. The efficacy of three different surgical techniques in the management of drug-induced gingival overgrowth. J Clin Periodontol 2006;33: 677-82. 